\title{
THE KALMAN FILTER IN \\ THE EVENT-STUDY \\ METHODOLOGY
}

\author{
Gerardo Dubcovsky* \\ Departamento de Contabilidad y Finanzas, Tecnológico de Monterrey, \\ Campus Ciudad de México \\ Francisco Venegas-Martínez \\ Centro de Investigación en Finanzas, Tecnológico de Monterrey, \\ Campus Ciudad de México
}

(Received 18 November 2002, accepted 20 January 2003)

\begin{abstract}
The purpose of this paper is to extend the event-study methodology, into a richer dynamic environment, by including time-varying parameters. We use the Kalman filter to model parameters depending on time in a state-space representation of the statistical market model of the event-study analysis. We also apply Bayesian inference to updating relevant information, and we use information theory to choose the initial distribution of parameters. The proposed extension leads to a more robust set-up in appraising the impact of economic, and financial events on the market value of firms.
\end{abstract}

\section{Resumen}

El propósito de este trabajo de investigación consiste en extender la metodología de estudios de eventos, en un ambiente dinámico más rico, a fin de que se incluyan parámetros dependientes del tiempo. Se utiliza el filtro de Kalman para modelar parámetros como función del tiempo, en una representación espacio-estado del modelo estadístico de mercado de estudios de eventos. Asimismo, se aplica inferencia Bayesiana para actualizar la información relevante y se utiliza la teoría de información para elegir la distribución inicial de los parámetros. La extensión propuesta conduce a un planteamiento más robusto de la evaluación del impacto que un evento económico o financiero tiene sobre el valor de mercado de las empresas.

JEL classification: G14

Keywords: Event studies, Kalman filtering, Information theory

* Departamento de Contabilidad y Finanzas, Tecnológico de Monterrey, Campus Ciudad de México, Calle del Puente 222, Oficinas 3, Segundo piso, Col. Ejidos de Huipulco, Del. Tlalpan, 14380 México, D. F., Teléfono: +52(55)54832232, E-mail: gdubcovs@itesm.mx

The authors are grateful to the anonymous referees for their comments. 


\section{Introduction}

Financial analysts are often concerned with measuring the effect of an economic or financial event on the market value of a specific firm. The most common approach to assess the impact of a certain event on the firm performance is the event-study analysis, which uses financial market data. In this methodology, the effect of an event will be related to the short-run returns of the assets available in the economy.

The literature in the event-study methodology is large, and applications range in a wide variety of events and firms; for instance, mergers, alliances, joint ventures, acquisitions, new debt, new stock, splits, payment of dividends, new regulation, etcetera. Even though there is not a unique structure of an event study, we may summarize the following main steps: 1) define the event of interest, 2) determine the event window, 3) select the firm, 4) define the normal and abnormal returns, 5) estimate parameters, 6) test for abnormal returns, and 7) provide interpretations of the results. Since the pioneer paper of Dolley (1933), the level of sophistication of the event-study analysis has dramatically increased. Important contribution to the theory, and practice of event studies can be found in Myers, and Bakay (1948); Barker (1956); Ashley (1962); Ball, and Brown (1968); Brown, and Warner (1985); among others. More recent work in the event-study analysis is due to Gilley, Worrel, and El-Jelly (2000) in investigating on the influence of environmental regulation on firms; Shelton (2000), in developing a framework to derive the demand, and supply of target firms in merger; Brady, and Feinberg (2000), in examining stock-price effects of the European Union merger control policy; Lambdin (2001), in implementing, and interpreting event studies of regulatory changes; Cowan, and Seargent (2001), in examining long-horizon event studies; Wilcox, Chang, and Grover (2001), in evaluating the impact of the numerous mergers, and alliances within the telecommunications industry.

Even though much knowledge has been gained about the impact of corporate news announcements from domestic, and foreign firms in Mexico during 1993-1995, much still remains to be learned. Needless to say, the Mexican experience of 1993-1994 (up until the December 1994 financial debacle) has been a central issue for some time. Let us highlight some of the financial, economic and political events of the Mexican economy between 1993, and 1994. During this period Mexico had an intense trade opening combined with a high degree of capital mobility. At the same time, the government built up a large debt relying on a privatization process, and a stabilization program. The government predetermined the rate of devaluation as a nominal anchor to stabilize inflation. There were several slight modifications to the original exchange-rate policy, including a mild increase in the rate of devaluation, and the adoption of an adjustable band that was gradually widened keeping constant the lower limit. During 1993-1994, a climate of political uncertainty was developed as a result of the following events: the Zapatista guerrilla uprising in Chiapas, the assassination of a presidential candidate, a weak "Pacto", a slowdown in exports, recommendations from specialists to devaluate in order to ease an overvalued currency, an increase in the interest of US government bonds, and approaching elections. In 1994, Mexico ran its worst trade deficit of the century. By the beginning of 1995, Mexico had abandoned the adjustable band system, and shifted 
to a managed floating exchange-rate. As a consequence, several corporate news announcements from domestic, and foreign firms in Mexico were carried out (mergers, acquisitions, and joint ventures). Since then, various event studies have been developed to evaluate the impacts on the market firms (sce Dubcovsky, and García, 1996; and Bhattacharya, Daouk, and Kehr, 2000). However, in most of the findings, there are contrasting results which may be due to modeling with time-independent parameters.

The growing economic importance of Latin American emerging markets, characterized by singular institutional, and regulatory frameworks, provides an interesting environment to evaluate the effects of financial, and economic events on the market value of firms. These markets exhibit high (expected) returns as well as high volatility, and little is known about the short and long-term effects of such effects. Even though a time-varying parameter formulation of the event-study methodology seems to be more realistic, there is no attempt in the existing literature to extend such a methodology in this direction. In this paper, we extend the event-study methodology into a richer dynamic environment by including time-varying parameters. Under the Bayesian framework, useful to update relevant information in a sequential learning mechanism, we use the Kalman filter to consider time dependent parameters to measure the effect of an economic or financial event on the market value of firms. In this context, we choose the initial distribution by using an information theory framework.

The Kalman Filter (KF) introduced by Kalman (1960); Kalman, and Bucy (1961); and independently by Swerling (1959), and Stratonovich (1960), has been successfully used in economics, and finance. Some of its numerous applications in these fields can be appreciated in Athans (1974); Burmeister and Wall (1982); Burmeister, Wall, and Hamilton (1986); Sargent (1989); Başar, and Salmon (1989); and Venegas-Martínez et al. (1995), and (1999); among others.

Our approach in presenting the KF uses information theory which has been extensively applied in economics, and finance. We mention, for instance: Theil, Scholes, and Uribe (1965); Theil, and Uribe (1965); Uribe, De Leeuw, and Theil (1965); Cozzolino, and Zahner (1973); Akaike (1981); Kapur (1990); Venegas-Martínez (1990), (1990a), (1990b), and (1993); and Venegas-Martínez et al. (1995), and (1999). We start off the recursive procedure of the KF by determining, via information theory, an estimator of the initial distribution when there is information in terms of moments, and then we use Bayesian inference to state the updating process of the KF. We think that under this framework the presentation is more attractive to financial analysts. It is worth pointing out that our approach to obtain the $\mathrm{KF}$ is simpler than those from Ho, and Lee (1964); and Meinhold, and Singpurwalla (1983).

The structure of this paper is as follows. In the next section, we briefly review the state-space models. In section 3, we outline the relationship between the KF with both information theory, and Bayesian inference. In section 4, we present the most popular statistical models for measuring normal returns. In section 5 , we extend the event-study analysis by including parameters that change with time. In section 6 , we provide a discussion about Kalman filtering, and normal and abnormal returns. Finally, in section 7, we give conclusions, acknowledge limitations, and make suggestions for further research. 


\section{The Kalman Filter}

In this section, we briefly introduce the state-space representation, the measurement and state equations of a dynamic system. We focus our attention in the multivariate case. In what follows all vectors, and matrices are assumed to be of consistent dimensions.

\subsection{The State-Space Representation}

Let $Y_{1}, Y_{2}, \ldots, Y_{t}$ be a set of indirect measurements from a polling system or a sample survey of an unobserved state variable $\beta_{t}$. The objective is to make inferences about $\beta_{t}$. We may think of $Y_{t}$, and $\beta_{t}$ as either scalars or vectors with dimensions which may be the same or different. The relationship between $Y_{t}$, and $\beta_{t}$ is specified by the measurement equation, sometimes also called the observation equation

$$
Y_{t}=X_{t} \beta_{t}+\varepsilon_{t}
$$

where $X_{t}$ is a matrix of known parameters, and $\varepsilon_{t}$ is the observation error distributed as $\mathcal{N}\left(0, \Sigma_{\varepsilon_{t}}\right)$, with $\Sigma_{\varepsilon_{t}}$ known. Since the variance changes over time we have, in general, a heteroscedastic error model. Notice that the main difference between the measurement equation, and the conventional linear model is that in the former, the coefficient $\beta_{t}$ changes with time.

The most popular dynamic extension of the error term in the conventional linear model states that

$$
\left\{\begin{array}{l}
Y_{t}=X_{t} \beta+\varepsilon_{t}, \\
\varepsilon_{t}=Z \varepsilon_{t-1}+\eta_{t},
\end{array}\right.
$$

where $Z$ is a matrix of known parameters, and $\eta_{t}$ is distributed as $\mathcal{N}\left(0, \Sigma_{\eta_{t}}\right)$. Notice that $\beta$ and $\Sigma_{\eta_{t}}$ are time invariant. The KF will not be concerned with the dynamics of the error term, $\varepsilon_{t}$, as in (2.2), but instead with the dynamics of the state variable, $\beta_{t}$, in (2.1). This being the other essential difference from the conventional linear model. We suppose that the dynamic behavior of the state variable $\beta_{t}$ is driven by a first order autoregressive process, that is,

$$
\beta_{t}=\mu_{t-1}+Z_{t} \beta_{t-1}+\eta_{t-1}
$$

where the drift $\mu_{t-1}$ is a vector of exogenous or predetermined variables, $Z_{t}$ is a matrix of known parameters, and $\eta_{t} \sim \mathcal{N}\left(0, \Sigma_{\eta_{t}}\right)$, with $\Sigma_{\eta_{t}}$ known. Or even more generally,

$$
\beta_{t}=\mu_{t-1}+Z_{t} \beta_{t-1}+L_{t} u_{t-1}+\eta_{t-1}
$$

where $L_{t}$ is a known matrix that relates the control inputs, $u_{t-1}$, to $\beta_{t}$. Equations (2.1) and (2.3) are known in the literature as the state-space representation of the dynamics of $\beta_{t}$. Throughout the paper, we shall assume that $\beta_{0}, \varepsilon_{t}$ and $\eta_{t}$ are independent random vectors, and $L_{t}=0$. We might state nonlinear versions of (2.1) and (2.3), but this would not make any essential differences in the analysis.

\section{Kalman Filtering, Information Theory, and Bayesian Inference}

In order to present the $\mathrm{KF}$ in a simple way, we first outline the principle of maximum entropy, and the Bayesian approach to statistical inference. The 
former will provide an estimator for the initial prior distribution to start off the sequential procedure of the $\mathrm{KF}$, and the latter will provide the recursive updating of information of the KF.

The principle of maximun entropy, first introduced by Jaynes (1957), provides a general method of inference about an unknown density, $p\left(\beta_{0}\right)$, when there is information about $p\left(\beta_{0}\right)$ in terms of moments. The principle states that among all compatible distributions with the available information, we should choose an estimate for $\pi\left(\beta_{0}\right), p\left(\beta_{0}\right)$, the one with the greatest entropy $-\int_{-\infty}^{\infty} \log \left(\pi\left(\beta_{0}\right)\right) \pi\left(\beta_{0}\right) \mathrm{d} \beta_{0}$.

Suppose that at time $t=0$, the available information is given by $\widehat{\beta}_{0}$ and $\widehat{\Sigma}_{0}$, the mean and variance of $\beta_{0}$, respectively. We may then use the principle of maximum entropy to find an estimate, $\pi\left(\beta_{0}\right)$, of the prior distribution of $\beta_{0}$ that takes into account the given information. The problem is as follows

$$
\begin{aligned}
& \text { Maximize }-\int_{-\infty}^{\infty} \log \left(\pi\left(\beta_{0}\right)\right) \pi\left(\beta_{0}\right) \mathrm{d} \beta_{0}, \\
& \text { subject to }\left\{\begin{array}{l}
\int_{-\infty}^{\infty} \pi\left(\beta_{0}\right) \mathrm{d} \beta_{0}=1, \\
\int_{-\infty}^{\infty} \beta_{0} \pi\left(\beta_{0}\right) \mathrm{d} \beta_{0}=\widehat{\beta}_{0}, \\
\int_{-\infty}^{\infty}\left(\beta_{0}-\widehat{\beta}_{0}\right)\left(\beta_{0}-\widehat{\beta}_{0}\right)^{T} \pi\left(\beta_{0}\right) \mathrm{d} \beta_{0}=\widehat{\Sigma}_{0} .
\end{array}\right.
\end{aligned}
$$

The first order condition of the above calculus of variations problem of maximum entropy is given by

$$
\pi\left(\beta_{0}\right) \propto \exp \left\{\lambda+\Lambda^{T} \beta_{0}+\left(\beta_{0}-\widehat{\beta}_{0}\right)^{T} L\left(\beta_{0}-\widehat{\beta}_{0}\right)\right\}
$$

where $\lambda$ is a scalar, $\Lambda$ is a vector, $L$ is a symmetric matrix and the superindex $T$ means the transpose operation. By substituting (3.1) in the constraints, we can show that $\beta_{0} \sim \mathcal{N}\left(\widehat{\beta}_{0}, \widehat{\Sigma}_{0}\right)$ (see, Venegas-Martínez (1990), and VenegasMartínez et al.(1995)).

Suppose now that, at time $t$, we wish to make inferences about the conditional state variable $\theta_{t}=\beta_{t} \mid I_{t}$, where $I_{t}=\left\{Y_{1}, Y_{2}, \ldots, Y_{t-1}\right\}$. In the Bayesian approach is to be assumed that there exists a prior density, $\pi\left(\theta_{t}\right)$, describing initial information. Once a prior has been prescribed, the information provided by the measurement $Y_{t}$, with density $p\left(Y_{t} \mid \theta_{t}\right)$, is used to modify the initial knowledge, as expressed by $\pi\left(\theta_{t}\right)$, via Bayes' theorem to obtain a posterior distribution of $\theta_{t}$, namely

$$
p\left(\theta_{t} \mid Y_{t}\right) \propto p\left(Y_{t} \mid \theta_{t}\right) \pi\left(\theta_{t}\right)
$$

The normalized posterior distribution is then used to make inferences about $\theta_{t}$. We are now in a position to state the recursive updating procedure of the KF. At time $t=0$, the maximum entropy estimator for the initial distribution, 
$\mathcal{N}\left(\widehat{\beta}_{0}, \widehat{\Sigma}_{0}\right)$, describes the initial knowledge of the system. Proceeding inductively, at time $t, \widehat{\beta}_{t-1}$ and $\widehat{\Sigma}_{t-1}$ become available information, and therefore prior knowledge at time $t$ is represented by

$$
\theta_{t}=\beta_{t} \mid I_{t} \sim \mathcal{N}\left(Z_{t} \widehat{\beta}_{t-1}, M_{t}\right),
$$

where

$$
M_{t}=Z_{t} \widehat{\Sigma}_{t-1} Z_{t}^{T}+\Sigma_{\eta_{t-1}} .
$$

The sampling model (or likelihood function) is determined by

$$
Y_{t} \mid \theta_{t} \sim \mathcal{N}\left(X_{t} \beta_{t}, \Sigma_{\varepsilon_{t}}\right) .
$$

The posterior distribution is then obtained by substituting both (3.3) and (3.5) in $(3.2)$, so

$$
\begin{aligned}
p\left(\theta_{t} \mid Y_{t}\right) & \propto \exp \left\{-\frac{1}{2}\left[\left(X_{t} \beta_{t}-Y_{t}\right)^{T} \Sigma_{\varepsilon_{t}}^{-1}\left(X_{t} \beta_{t}-Y_{t}\right)\right.\right. \\
& \left.\left.+\left(\beta_{t}-Z_{t} \widehat{\beta}_{t-1}\right)^{T} M_{t}^{-1}\left(\beta_{t}-Z_{t} \widehat{\beta}_{t-1}\right)\right]\right\} .
\end{aligned}
$$

Noting that $p\left(\theta_{t}\right)$ is a natural conjugate prior. We may complete the squares, which is a standard technique in Bayesian inference, to get

$$
\theta_{t} \mid Y_{t} \sim \mathcal{N}\left[Z_{t} \widehat{\beta}_{t-1}+K_{t}\left(Y_{t}-X_{t} Z_{t} \widehat{\beta}_{t-1}\right), M_{i}-K_{t} X_{t} M_{t}\right],
$$

where

$$
K_{t}=M_{t} X_{t}^{T}\left(\Sigma_{\varepsilon_{t}}+X_{t} M_{t} X_{t}^{T}\right)^{-1} .
$$

This, of course, means that

$$
\left\{\begin{array}{l}
\widehat{\beta}_{t}=Z_{t} \widehat{\beta}_{t-1}+K_{t}\left(Y_{t}-X_{t} Z_{t} \widehat{\beta}_{t-1}\right) \\
\widehat{\Sigma}_{t}=M_{t}-K_{t} X_{t} M_{t}
\end{array}\right.
$$

We then proceed with the next iteration. Equations (3.4), (3.6), and (3.7) are known in the literature as the KF. We warn the reader not to confuse the KF with the state-space representation given in (2.1) and (2.3).

By means of various vector-matrix manipulations, the matrix $K_{t}$ in (3.6) can be put into a number of equivalent forms. An alternative formulation, that we shall use in the next section, is given by

$$
K_{t}=\left(X_{t}^{T} \Sigma_{\varepsilon_{t}}^{-1} X_{t}+M_{t}^{-1}\right)^{-1} X_{t}^{T} \Sigma_{\varepsilon_{t}}^{-1} .
$$

To verify (3.8), we simply premultiply the right-hand side of (3.6) by a suitable choice of "identity" matrix as follows

$$
\begin{aligned}
K_{t} & =\left(X_{t}^{T} \Sigma_{\varepsilon_{t}}^{-1} X_{t}+M_{t}^{-1}\right)^{-1}\left(X_{t}^{T} \Sigma_{\varepsilon_{t}}^{-1} X_{t}+M_{t}^{-1}\right) M_{t} X_{t}^{T}\left(\Sigma_{\varepsilon_{t}}+X_{t} M_{t} X_{t}^{T}\right)^{-1} \\
& =\left(X_{t}^{T} \Sigma_{\varepsilon_{t}}^{-1} X_{t}+M_{t}^{-1}\right)^{-1} X_{t}^{T} \Sigma_{\varepsilon_{t}}^{-1}\left(\Sigma_{\varepsilon_{t}}+X_{t} M_{t} X_{t}^{T}\right)\left(\Sigma_{\varepsilon_{t}}+X_{t} M_{t} X_{t}^{T}\right)^{-1} \\
& =\left(X_{t}^{T} \Sigma_{\varepsilon_{t}}^{-1} X_{t}+M_{t}^{-1}\right)^{-1} X_{t}^{T} \Sigma_{\varepsilon_{t}}^{-1} .
\end{aligned}
$$




\subsection{Relationship with Generalized Least Squares}

In this section, we briefly discuss the KF relationship with the Generalized Least Squares methodology for both the classical and Bayesian approaches. We suppose that $\beta_{1}=\beta_{2}=\cdots=\beta_{t}, Z_{1}=I$, and $\Sigma_{\eta_{t}}$ does not appear. By simple computations involving the KF with (3.8), we find

$$
\begin{aligned}
\widehat{\beta}_{1} & =\widehat{\beta}_{0}+K_{1}\left(Y_{1}-X_{1} \widehat{\beta}_{0}\right) \\
& =\widehat{\beta}_{0}+\left(X_{1}^{T} \Sigma_{\varepsilon_{1}}^{-1} X_{1}+\Sigma_{0}^{-1}\right)^{-1} X_{1}^{T} \Sigma_{\varepsilon_{1}}^{-1}\left(Y_{1}-X_{1} \widehat{\beta}_{0}\right) \\
& =\left(X_{1}^{T} \Sigma_{\varepsilon_{1}}^{-1} X_{1}+\Sigma_{0}^{-1}\right)^{-1}\left[\left(X_{1}^{T} \Sigma_{\varepsilon_{1}}^{-1} X_{1}+\Sigma_{0}^{-1}\right) \widehat{\beta}_{0}+X_{1}^{T} \Sigma_{\varepsilon_{1}}^{-1}\left(Y_{1}-X_{1} \widehat{\beta}_{0}\right)\right] \\
& =\left(X_{1}^{T} \Sigma_{\varepsilon_{1}}^{-1} X_{1}+\Sigma_{0}^{-1}\right)^{-1}\left(\Sigma_{0}^{-1} \widehat{\beta}_{0}+X_{1}^{T} \Sigma_{\varepsilon_{1}}^{-1} Y_{1}\right),
\end{aligned}
$$

which is the posterior estimate for $\beta_{1}$, when initial information from a natural conjugate prior is available. Notice that when $\Sigma_{0}^{-1}$ vanishes (i.e., when the prior is not informative), the estimate is

$$
\widehat{\beta}_{1}=\left(X_{1}^{T} \Sigma_{\varepsilon_{1}}^{-1} X_{1}\right)^{-1} X_{1}^{T} \Sigma_{\varepsilon_{1}}^{-1} Y_{1},
$$

which is the Generalized Least Squares estimate of $\beta_{1}$.

\section{Statistical Models of Event Studies}

There are several models available in the literature to calculate the normal return of a given stock. These approaches can be grouped into two types: statistical and economic. In the former, there are statistical assumptions concerning the behavior of the asset returns. While, in the latter, there are assumptions on the behavior both economic agents, and asset returns. In particular, in the statistical type it is customary to assume that asset returns are distributed multivariate normal independently. A number of the statistical models have been proposed for measuring normal returns, we briefly review two of the most popular statistical models in event-studies.

\subsection{The Constant-Mean-Return Model}

The constant-mean-return framework is very popular in event-study analysis. Although the above framework is one of the models, it turns out that the obtained results are similar to those from more sophisticated models (see, for instance, Brown and Warner, 1985). Let $\mu_{i}$ be the mean return for asset $i$. Let us define

$$
R_{i t}=\mu_{i}+\varepsilon_{i t}
$$

where $R_{i t}$ is the return in period $t$ on the security $i$, and $\varepsilon_{i t}$ is white noise for each $i$, that is to say,

$$
\mathrm{E}\left[\varepsilon_{i t}\right]=0, \quad \operatorname{Var}\left[\varepsilon_{i t}\right]=\sigma_{i}^{2} .
$$

Plainly, the (unconditional) mean, and variance of $R_{i t}$ are given by

$$
\mathrm{E}\left[R_{i t}\right]=\mu_{i} \quad \operatorname{Var}\left[R_{i t}\right]=\sigma_{i}^{2} .
$$


Finally, it is important to point out that with monthly data, the model can be applied to real returns or excess returns as well as nominal returns.

\subsection{Market Model}

The market model relates the return of any given security to the return of the market portafolio. The model's linear specification follows from the assumed joint normality of the asset returns. Especifically, for any stock $i$, we have

$$
R_{i t}=\alpha_{i}+R_{m t} \gamma_{i}+\varepsilon_{i t}
$$

where $\varepsilon_{i t}$ is taken as in (4.2). Here, $R_{m t}$ is the return in period $t$ on the market portafolio. The coefficients $\alpha_{i}, \gamma_{i}$, and $\sigma_{i}^{2}$ are the relevant parameters of the model.

\section{Kalman Filtering in Event Studies}

The market model improves in several aspects the constant-mean-return model. For instance, by removing the portion of the return that is related to variations in the asset return, the variance of the abnormal return is reduced. This can lead to increased ability to detect event effects. The advantages from using the market model will depend upon the $R^{2}$ of the market-model regression. The higher the $R^{2}$, the greater the variance reduction of the abnormal return, and the larger the gain.

Let $R_{i 1}, R_{i 2}, \ldots, R_{i t}$ be a set of returns of the $i$-th asset, the relationship between the return, $R_{i t}$, and the time-varying coefficients, $\alpha_{i t}$ and $\gamma_{i t}$, is specified by the following measurement or observation equation

$$
R_{i t}=\alpha_{i t}+R_{m t} \gamma_{i t}+\varepsilon_{i t}=\bar{R}_{m t} \beta_{i t}+\varepsilon_{i t},
$$

where $\bar{R}_{m t}=\left(1, R_{m t}\right), \beta_{i t}=\left(\alpha_{i t}, \gamma_{i t}\right)^{T}$, and $\varepsilon_{i t}$ is the observation error distributed as $\mathcal{N}\left(0, \sigma_{i}^{2}\right)$, with $\sigma_{i}$ known. Notice that the main difference between the measurement equation and the market model is that, in the former, the vector of coefficients $\beta_{i t}$ changes with time. Furthermore, we suppose that $\beta_{i t}$ is driven by a first order autoregressive process, that is

$$
\beta_{i t}=Z_{i t} \beta_{i, t-1}+\eta_{i, t-1}
$$

where $Z_{t}$ is a known matrix, and $\eta_{t} \sim \mathcal{N}\left(0, \Sigma_{\eta}\right)$, with $\Sigma_{\eta}$ known. The objective is to make inferences about $\beta_{i t}$. In what follows, we will assume, as customary, that $\beta_{i 0}, \varepsilon_{i t}$, and $\eta_{i t}$ are stochastically independent.

Suppose now that, at time $t=0$, initial information is given by $\widehat{\beta}_{i 0}$ and $\widehat{\Sigma}_{i 0}$, the mean and the variance-covariance matrix of $\beta_{i 0}$, respectively. That is, initial information, $\mathcal{I}$, is given by

$$
I:\left\{\begin{array}{l}
\int_{-\infty}^{\infty} \pi\left(\beta_{i 0}\right) \mathrm{d} \beta_{i 0}=1 \\
\int_{-\infty}^{\infty} \beta_{i 0} \pi\left(\beta_{i 0}\right) \mathrm{d} \beta_{i 0}=\widehat{\beta}_{0} \\
\int_{-\infty}^{\infty}\left(\beta_{i 0}-\widehat{\beta}_{i 0}\right)\left(\beta_{i 0}-\widehat{\beta}_{i 0}\right)^{T} \pi\left(\beta_{0}\right) \mathrm{d} \beta_{i 0}=\widehat{\Sigma}_{i 0}
\end{array}\right.
$$


In this case, the initial prior that maximizes entropy is

$$
\pi\left(\beta_{i 0}\right) \propto \exp \left\{(1-\phi) \mathcal{F}\left(\beta_{i 0}\right)+\lambda_{i 0}+\lambda_{i 1} \beta_{i 0}+\lambda_{2}\left(\beta_{i 0}-\widehat{\beta}_{i 0}\right)^{T} \Lambda_{i 2}\left(\beta_{i 0}-\widehat{\beta}_{i 0}\right)\right\},
$$

where $\lambda_{i 0}, \lambda_{i 1}$, and $\Lambda_{i 2}$ are the Lagrange Multipliers associated with the constraints.

Suppose that, at time $t$, we wish to make inferences about the conditional state variable $\theta_{i t}=\beta_{i t} \mid I_{i t}$, where $I_{i t}=\left\{R_{i 1}, R_{i 2}, \ldots, R_{i, t-1}\right\}$. To obtain a posterior distribution of $\theta_{i t}$, the information provided by the measurement $R_{i t}$, with density $f\left(R_{i t} \mid \theta_{i t}\right)$, is used to modify the initial knowledge in $\pi\left(\theta_{t}\right)$ according to Bayes' theorem:

$$
f\left(\theta_{i t} \mid R_{i t}\right) \propto f\left(R_{i t} \mid \theta_{i t}\right) \pi\left(\theta_{i t}\right) .
$$

We now are in a position to state the Baycsian recursive updating procedure of the KF. To start off the KF procedure, we substitute (5.4) in $(5.3)$, so the initial prior, at time $t=0$, is given by $\mathcal{N}\left(\widehat{\beta}_{i 0}, \widehat{\Sigma}_{i 0}\right)$, which describes the initial knowledge of the system. Proceeding inductively, at time $t, \widehat{\beta}_{i, t-1}$ and $\widehat{\Sigma}_{i, t-1}$ become additional information, and therefore the prior, at time $t$, is given by

$$
\theta_{i t}=\beta_{i t} \mid I_{i t} \sim \mathcal{N}\left(Z_{i t} \widehat{\beta}_{i, t-1}, M_{i t}\right),
$$

where

$$
M_{i t}=Z_{i t} \widehat{\Sigma}_{i, t-1} Z_{i t}^{T}+\Sigma_{\eta} .
$$

The sampling model (or likelihood function) is determined by

$$
R_{i t} \mid \theta_{i t} \sim \mathcal{N}\left(\bar{R}_{m i} \beta_{i t}, \sigma_{\varepsilon}^{2}\right)
$$

The posterior distribution, at time $t$, is then obtained by substituting both (5.6), and (5.7) in (5.5), so

$$
\begin{aligned}
f\left(\theta_{i t} \mid \bar{R}_{i t}\right) & \propto \exp \left\{-\frac{1}{2}\left[\left(R_{m t} \beta_{t}-R_{i t}\right)^{2} \sigma_{\varepsilon}^{-2}\right.\right. \\
& \left.\left.+\left(\beta_{i t}-Z_{i t} \widehat{\beta}_{i, t-1}\right)^{T} M_{i t}^{-1}\left(\beta_{i t}-Z_{i t} \widehat{\beta}_{i, t-1}\right)\right]\right\} .
\end{aligned}
$$

Noting that $\pi\left(\theta_{i t}\right)$ is a natural conjugate prior, it follows that

$$
\theta_{i t} \mid R_{i t} \sim \mathcal{N}\left[Z_{i t} \widehat{\beta}_{i, t-1}+K_{i t}\left(R_{i t}-\bar{R}_{m t} Z_{i t} \widehat{\beta}_{i, t-1}\right), M_{i t}-K_{i t} \bar{R}_{m t} M_{i t}\right]
$$

where

$$
K_{i t}=M_{i t} \bar{R}_{m t}^{T}\left(\sigma_{\varepsilon_{t}}^{2}+\bar{R}_{m t} M_{t} \bar{R}_{m t}^{T}\right)^{-1}
$$


This, of course, means that

$$
\left\{\begin{array}{l}
\widehat{\beta}_{i t}=Z_{i t} \widehat{\beta}_{i, t-1}+K_{t}\left(R_{i t}-\bar{R}_{m t} Z_{t} \widehat{\beta}_{i, t-1}\right) \\
\widehat{\Sigma}_{i t}=M_{i t}-K_{i t} \bar{R}_{m t} M_{i t} .
\end{array}\right.
$$

We then proceed with the next iteration. Equations $(5.7),(5.9)$, and $(5.10)$ are known in the literature as the $\mathrm{KF}$.

\section{Kalman Filtering, Event Window, and Abnormal Returns}

After defining the event of interest, and identifying the period over which the stock prices of the firms involved in this event will be examined, to assess the impact of the event we requiere a measure of the abnormal return. The abnormal return is the actual ex post return of the stock over the event window minus the normal return of the firm over the event window. Hence, the normal return is defined as the return that would be expected if the event did not take place. Thus, for firm $i$, and event date $t$, we have that

$$
\varepsilon_{i t}^{*}=R_{i t}-\mathrm{E}\left[R_{i t} \mid \bar{R}_{m t}\right]
$$

where

$$
R_{i t}=\bar{R}_{m t} \beta_{i t}+\varepsilon_{i t}
$$

and

$$
\beta_{i t}=Z_{i t} \beta_{i, t-1}+\eta_{i, t-1}
$$

defines the abnormal returns at time $t$. Finally, estimators of the time-varying parameters satisfy

$$
\widehat{\beta}_{i t}=Z_{i t} \widehat{\beta}_{i, t-1}+K_{t}\left(R_{i t}-R_{m t} Z_{t} \widehat{\beta}_{i, t-1}\right) .
$$

\section{On the Null Hypothesis}

So far, we have emphasized on a single null hypothesis $H_{0}$ : that the given event has no impact on the behavior of stock returns. Under $H_{0}$ either a mean effect or a variance effect represents a violation. However, in many cases we may be interested in testing only for a mean effect. In these cases, we need to extend $H_{0}$ to allow for changing variances. To achieve this goal, we have to eliminate the dependence on past security returns in estimating the variance of the agregated cumulative abnormal returns. In such a case, we use the cross section of cumulative abnormal returns to form an estimator of the variance, which is best applied when using the model

$$
\left\{\begin{array}{l}
R_{i t}=\bar{R}_{m t} \beta_{i t}+\varepsilon_{i t}, \\
\beta_{i t}=Z_{i t} \beta_{i, t-1}+\eta_{i, t-1}
\end{array}\right.
$$

to measure abnormal security returns.

Variance estimation by using cross-sectional analysis can be applied to both the average cumulative abnormal return, $\overline{C A R}\left(\tau_{1}, \tau_{2} ; \widehat{\beta}_{i t}\right)$, and the average 
standardized cumulative abnormal return, $\overline{S C A R}\left(\tau_{1}, \tau_{2} ; \hat{\beta}_{i t}\right)$. In these cases, estimators of the variances are given, respectively, by

$$
\widehat{\operatorname{Var}}\left[\overline{C A R}\left(\tau_{1}, \tau_{2} ; \widehat{\beta}_{i t}\right)\right]=\frac{1}{N^{2}} \sum_{i=1}^{N}\left[C A R_{i}\left(\tau_{1}, \tau_{2} ; \widehat{\beta}_{i t}\right)-\overline{C A R}\left(\tau_{1}, \tau_{2} ; \widehat{\beta}_{i t}\right)\right]^{2} \text {, }
$$

and

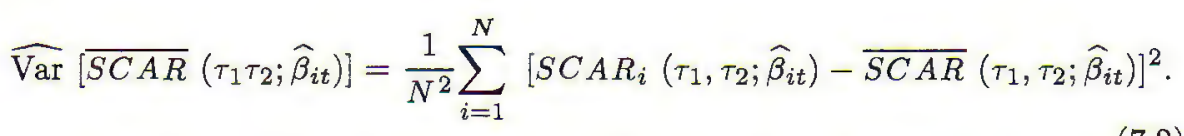

For these estimators of the variances to be consistent, we require the abnormal returns to be uncorrelated in the cross-section. It is important to point out that an absence of clustering is enough for this requirement. Notice also that cross-sectional homoscedasticity is not required for consistency.

\section{Summary and Conclusions}

Even though the event-study methodology has been widely used to study a variety of firms and events, it has been missing an extension considering timevarying parameters. In this research, we have extended the event-study methodology, into a richer dynamic environment, by including parameters that change over time. Our proposal, which uses the Kalman Filter, leads to a more robust set-up to measure the impact of economic, and financial events on the market value of firms. Needless to say, it remains to be done some empirical work on using our methodology. To do so, we will devote ourselves to elaborate some empirical analysis for the Mexican case in several coming papers. Our theoretical framework encourages, and suggests further research in several directions. For instance, it is crucial to investigate how the effects display long-run trends that affect the market value of the firms.

\section{References}

Ashley, J. W. (1962). Stock Price and Changes in Earnings and Dividends: Some Empirical Results. Journal of Political Economy, 70, pp. 82-85.

Athans, M. (1974). The Importance of Kalman Filtering Methods for Economic System. Annals of Economics and Social Measurements, 3, pp. 49-74.

Akaike, H. (1981). Likelihood of a Model and Information Criteria. Journal of Econometrics, 16, pp. 3-14.

Ball, R., and P. Brown (1968). An empirical Evaluation of Accounting Income Numbers. Journal Accounting Research, 6, pp.159-78.

Barker, C. A. (1956). Effective Stock Splits. Harvard Business Review, 34, pp. 101-06.

Başar, T., and M. Salmon (1989). On the Convergence of Beliefs and Policy to a Rational Expectations Equilibrium in a Dual Policy Problem. Springer Verlag, pp. 207-223.

Bhattacharya, U., B. Daouk, and C. Kehr (2000). When an Event is not an Event: The Curious Case of an Emerging Market. Journal of Financial Economics, 55, pp. 69-101.

Brady, U., and R. M. Feinberg (2000). An Examination of Stock-Price of EU Merger control Policy. International Journal of Industrial Organization, 18, pp. 885-900.

Brown, S., and J. B. Warner (1985). Using Daily Stock Returns: The Case of Event Studies. Journal of Financial Economics, 14, pp. 3-31. 
Burmeister, E., and K. D. Wall (1982). Kalman Filtering Estimations of Unobserved Rational Expectations with one Application to the German Hyperinflation. Journal of Econometrics, 20, pp. 255-284.

Burmeister, E., K. D. Wall, and J. D. Hamilton (1986). Estimations of Unobserved Expected Monthly Inflation Using Kalman Filtering. Journal of Business and Economic Statistics, 4, pp. 147-160.

Cowan, A., and A. Seargent (2001). Interacting Biases, Non-Normal Return Distributions and the Performance of Test for Long-Horizon Event Studies. Journal of Banking and Finance, 25, pp. 741-765.

Cozzolino, J., and M. Zahner (1973). The Maximum-Entropy Distribution of the Future Market Price of Stock. Operations Research, 21, pp. 1200-1211.

Dolley, J. (1933). Characteristics and Procedure of Common Stock Split-Ups. Harvard Business Review, 11, pp. 316-26.

Dubcovsky, G., and B. García (1996). The Effects of Mergers, Acquisitions and Joint Ventures between US-Mexican Firms (1993-1994): An Empirical Analysis Using the Event-Study Methodology. Inversión y Finanzas, 4(1), pp. 35-49.

Gilley, K., D. Worrel, and A. El-Jelly (2000). Corporate Environmental Initiatives and Anticipated Firm Performance: The Differential Effects of Process-Driven Versus ProductDriven Greening Iniatitives. Journal of Management, 26, pp. 1199-1216.

Ho, Y., and R. Lee (1964). A Bayesian Approach to Problems in Stochastic Estimation and Control. IEEE Trans. Automat. Contr., AC-9, pp. 333-339. pp. 620-630.

Jaynes, E. (1957). Information Theory and Statistical Mechanics I, Physics Review, 106, pp. $620-630$.

Kalman, R. (1960). A New Approach to Linear Filtering and Prediction Problems, Transactions ASME, Series D. Journal of Basic Engineering, 82, pp.35-45.

Kalman, R., and R. Bucy (1961). New Results in Linear Filtering and Prediction Theory, Transactions ASME, Series D. Journal of Basic Engineering, 83, pp.95-108.

Kapur, J. (1990). Maximum Entropy Models in Science and Engineering, John Wiley. pp. 593-602.

Lambdin, D. (2001). Implementing and Interpreting Event Studies of Regulatory Changes. Journal of Economics and Business, 53, pp. 171-183.

Meinhold, R., and N. Singpurwalla (1983). Understanding the Kalman Filter. The American Statistician, 37, pp. 123-127.

Morck, R, B Yeung, and W. Yu (2000). The Information Content of Stock Markets: Why Do Emerging Economics Have Synchronous Stock Price Movements ?. Journal of Financial Economics, 58, pp. 215-260.

Myers, J., and A. Bakay (1948). Influence of Stock Split-Ups on Market Price, Harvard Business Review, 26, pp. 251-55.

Sargent, T. (1989). Two Models of Measurements and the Investment Accelerator. Journal of Political Economy, 97, pp. 251-287.

Shelton, L. (2000). Merger Market Dynamics: Insights into the Behavior of Target and Bidder Firms. Journal of Economic Behavior and Organization, 41, pp. 363-383.

Stratonovich, R. (1960). Applications of the Theory of Markoff Processes in Optimal Signal Detection. Radio Eng. Electron. Phys., 1, pp. 1-19.

Swerling, P. (1959). First Order Error Propagation in a Stagewise Smoothing Procedure for Satellite Observations. Journal Astronautical Science 6, pp. 46-52.

Theil, H., and P. Uribe (1965), The Information Approach to the Aggregation of InputOutput Tables.Report 6503 of the Center for Mathematical Studies in Business and Economics. The University of Chicago.

Theil, H., M. Scholes, and P. Uribe (1965). An Informational Approach to the Measurement of Industrial Concentration, Report 6512 of the Center for Mathematical Studies in Business and Economics. The University of Chicago.

Uribe, P., C. De Leeuw, and H. Theil (1965). The Informational Approach to the Prediction of Interregional Trade Flows. Report 6507 of the Econometric Institute of the Netherlands School of Economics. 
Venegas-Martínez, F. (1990). Información Suplementaria a Priori, Aspectos Computacionales y Clasificación, Estadística, Inter-American Statistical Institute, IASI, 42, pp. 64-80.

Venegas-Martínez, F. (1990a). Supplementary Prior Information. Contributions to Probability and Mathematical Statistics, 4, pp. 228-237.

Venegas-Martínez, F. (1990b). On Regularity and Optimality Conditions for Maximum Entropy Priors. The Brazilian Journal of Probability and Statistics, 4, pp. 105-136.

Venegas-Martínez, F. (1992). Entropy Maximization and Cross-Entropy Minimization on Quantiles: A Matrix Approach. Agrociencia, Serie Matemáticas Aplicadas, Estadística y Computación, 3, pp. 71-76.

Venegas-Martínez, F. (1993). Learning on Utility Parameters. Recent Advances in Bayesian Statistics and Econometrics, 2, pp. 65-83.

Venegas-Martínez, F., E. de Alba, and M. Ordorica-Mellado (1995). An Economist's Guide to The Kalman Filter. Estudios Económicos, 10, pp. 123-145.

Venegas-Martínez, F., E. de Alba, and M. Ordorica-Mellado (1999). On Information, Priors, Econometrics, and Economic Modeling. Estudios Económicos, 14, pp. 123-145.

Wilcox, H., K. Chang, and V. Grover (2001). Valuation of Mergers and Acquisitions in the Telecommunications Industry: A Study on Diversification and Firm Size. Information and Management, 38, pp. 459-471. 